\title{
Sciendo
}

DOI: 10.2478/rgg-2019-0009

Received: 2 August 2019 / Accepted: 20 November 2019

Published online: 2 December 2019

\section{Deformation analysis in central west Bulgaria using triangulation and GPS data}

\author{
Nikolay Dimitrov ${ }^{1 *}$ \\ ${ }^{1}$ Department of Geodesy, National Institute of Geophysics, Geodesy and Geography, Acad. G. Bonchev str., \\ Block 3, Sofia 1113, Bulgaria \\ *ndimitrov@geophys.bas.bg
}

\begin{abstract}
The article discusses a method applied for combining the results of Global Navigation Satellite Systems (GNSS) and 75-year old triangulation measurements to estimate the crustal movements in central western Bulgaria region. It was examined for joint analysis based on the results of GNSS with angular measurements of the first order triangulation network in Bulgaria during the period 1923-1930 year. As a result of the processing of GNSS and angular measurements, horizontal velocities of 15 points, strain rates, and rotation rates have been obtained. The results show dominating N-S extension at a rate of 1-2 $\mathrm{mm} / \mathrm{y}$ and the deformation is not uniformly distributed over the studied area. The obtained results indicate the possibility of using old angular measurement of first-order triangulation points, together with GNSS data, to obtain estimates of the horizontal crustal movements.
\end{abstract}

Key words: deformation analysis, GNSS, triangulation, active tectonics

\section{Introduction}

GNSS is a technique that is a useful for studies on active tectonic because it provides quantitative information on kinematic and deformation parameters in the studied areas. Static GNSS measurements are used to determine the crustal movements. GNSS measurements allow observation of the recent tectonic activity because they provide quantitative assessments of crustal movements in studied areas. Previous studies have shown the applicability of such a method in geodynamic areas with high horizontal and vertical deformation rates such as the western United States (Dong et al., 1998), central west Bulgaria (Dimitrov and Georgiev, 2011), Central Valley, California (Romero and Berber, 2018) and so on. Global Positioning System (GPS) data provide a good opportunity to study the current geodynamic processes, but the basic question arising in this case is how far the present-day results can be extrapolated back in time. An approach to address this question is to integrate GNSS with historical triangulation data in spite of the fact that the positional accuracy of the old triangulations is usually in the range of $10-15 \mathrm{~cm}$ which is much lower, than the accuracy of the GPS measurements. The region of central western Bulgaria is of particular interest because of the high population density and high concentration of industrial resources so it is necessary to carry out the research of crustal movements in the area.

\section{GPS measurements}

GPS measurements of eight points in a region of central western Bulgaria carried out by specialists from the Department of Geodesy at National Institute of Geophysics, Geodesy and Geography (NIGGG, Bulgarian Academy of Science) in several periods between 1997 and 2006 is used in the estimation. The measured points are part of the established in 1996 geodynamic GPS network in the region within a joint project with the Massachusetts Institute of Technology (Kotzev et al., 2006). All points are stabilised with metal bolts in typical rocks after geological field study. Additional GPS measurements were carried out of seven points of the first-order Bulgarian triangulation network (Fig. 1). The epochs of the GPS measurements is shown in Table 1. 
Table 1. Epoch of GPS measurements

\begin{tabular}{lccccc}
\hline \multirow{5}{*}{ ID } & \multicolumn{5}{c}{ Epoch } \\
\cline { 2 - 6 } & 1997 & 2000 & 2003 & 2005 & 2006 \\
\hline BREZ & $\mathrm{X}$ & $\mathrm{X}$ & & & \\
BUHO & $\mathrm{X}$ & $\mathrm{X}$ & & & \\
LOZE & $\mathrm{X}$ & $\mathrm{X}$ & & & \\
SLIV & $\mathrm{X}$ & $\mathrm{X}$ & & & \\
VERI & $\mathrm{X}$ & $\mathrm{X}$ & & & \\
VLAD & $\mathrm{X}$ & $\mathrm{X}$ & & & \\
PLA1 & $\mathrm{X}$ & $\mathrm{X}$ & & & \\
0082 & & & $\mathrm{X}$ & & \\
0081 & & & $\mathrm{X}$ & & \\
0083 & & & $\mathrm{X}$ & & \\
0017 & & & $\mathrm{X}$ & & \\
0011 & & & $\mathrm{X}$ & & \\
0012 & & & $\mathrm{X}$ & & \\
0016 & & & $\mathrm{X}$ & & \\
0026 & & & $\mathrm{X}$ & $\mathrm{X}$ & $\mathrm{X}$ \\
\hline
\end{tabular}

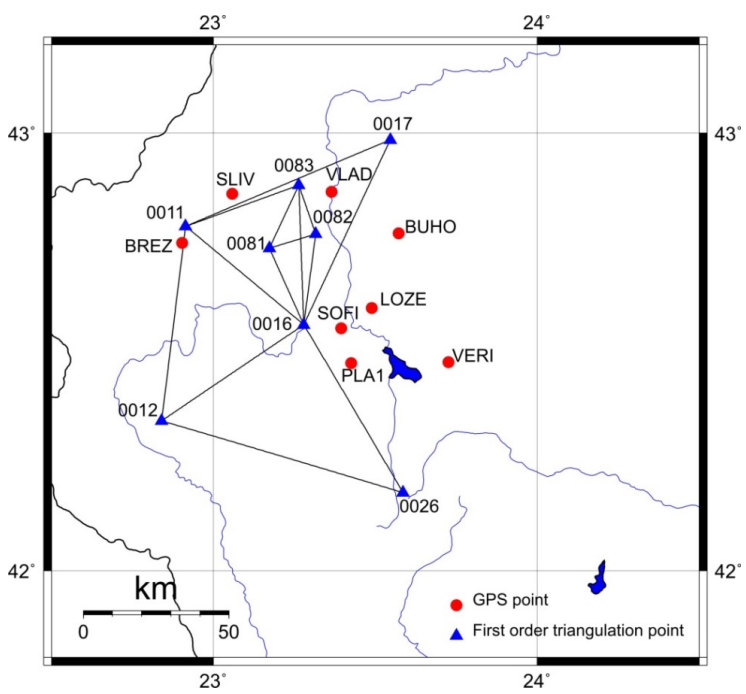

Figure 1. Map of the analysed area and positions of the network stations.

\section{Triangulation data}

Bulgarian first-order triangulation measurements were carried out between 1921 and 1929. Most of the measurements were made between 1927 and 1929 using Hildebrand and Bamberg precise theodolites. The scale and orientation of the triangulation were controlled from four bases measured with Invar wires between 1928 and 1929. The used observations of the 1928 survey (Yearbook of the State Geographic Institute, 1927, 1929,1932 ) consist of theodolite directions measured by the method of Schreiber with standard error of the mean of 0.3 arc seconds.

In Figure 1, points from geodynamic GPS network are shown with circles, points from Bulgarian first-order triangulation network with triangles and measured directions with lines.

\section{Combination of triangulation and GPS data}

The approach described by Dong et al. (1998) is followed in this study to combine triangulation and GPS data. The loosely constrained estimates for the station positions from the triangulation data were computed using the FONDA software (Dong, 1993). Those estimates and their covariance matrix were in-

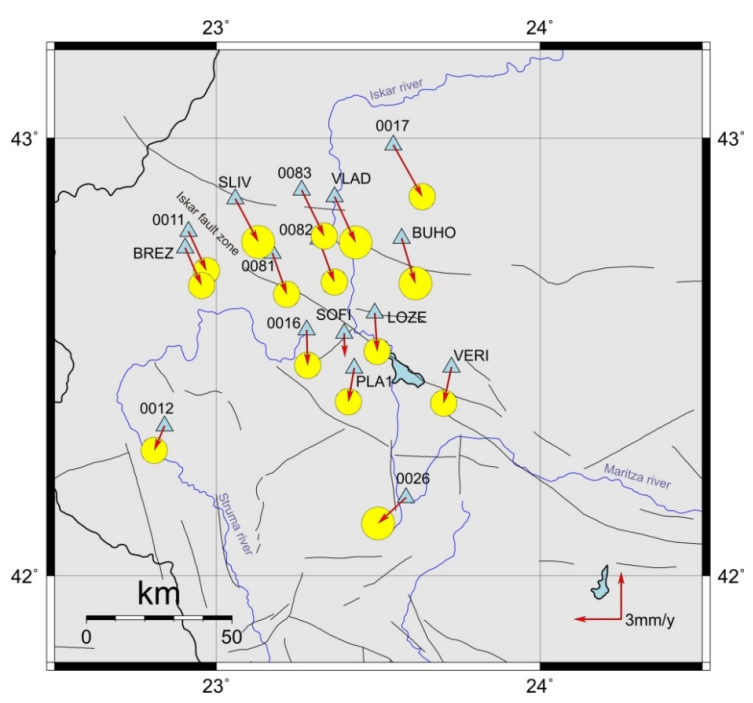

Figure 2. Velocities of points with respect to stable Eurasia obtained from the analysis of GPS and triangulation data.

troduced as quasi-observations at the second stage of the GPS processing to recombine with the GPS data. The triangulation and GPS networks have been tied together imposing the triangulation stations 0011 and 0083 to have the same horizontal velocities as the nearby GPS stations BREZ and VLAD. Points coordinates and velocities have been estimated (Fig. 2) together with the principal strain axes (Fig. 3), magnitudes and directions of rotation in Delaunay triangles (Fig. 4).

\section{Results and discussion}

As results of the combined GPS and triangulation data solution, the velocities with respect to the Eurasia of all 15 points are obtained and values are given in Table 2, where $V_{x}, V_{y}$ and $V_{z}$ are the $x, y$ and $z$ component of velocity in geocentric reference frame, respectively; $V_{n}$ and $V_{e}$ are the north and east component of velocity in topocentric reference frame, respectively; and $m_{i}$ is the accuracy of corresponding velocity component. Horizontal velocities are shown in Figure 2 along with $3 \sigma$ error ellipses. The slim lines show active faults in the region (Barrier et al., 2004). Figure 3 shows the principal axes of the horizontal strain rate tensors in central west Bulgaria resulted from combined GPS and triangulation data solution. In Figure 4 the rotation rates in Delaunay triangles are shown.

It is evident that the general tendency of movement of the points in the region of central west Bulgaria is in the south direction, which is in line with the extensive movement of southern Bulgaria and northern Greece (Burchfiel et al., 2000). Although the different configuration of the network, some of the results in Kotzev et al. (2005) have been confirmed, the stations with combined GPS-triangulation velocities show similar behaviour as the GPS stations. This clearly indicates the compatibility between longer- and shorter-time active deformations of the land.

Even if small, the obtained relative motions between the points show some tendencies - station 0016 shows velocity very similar to the velocities for the closest stations. The velocity for station 0016 is quite reliable because the first closely located station PLA1 is very well observed and the second, SOFI, is a permanent GNSS station with long data time span. Combination of triangulation and GPS networks by imposing the triangulation stations 0011 and 0083 to have the same horizontal velocities as the nearby GPS stations, BREZ and VLAD give more reliable result compared with that of Dimitrov and 
Table 2. Velocities of points with respect to stable Eurasia

\begin{tabular}{lrrrrrrrrrr}
\hline ST & $\begin{array}{c}V_{x} \\
{[\mathrm{~mm} / \mathrm{y}]}\end{array}$ & $\begin{array}{c}m_{x} \\
{[\mathrm{~mm}]}\end{array}$ & $\begin{array}{c}V_{y} \\
{[\mathrm{~mm} / \mathrm{y}]}\end{array}$ & $\begin{array}{c}m_{y} \\
{[\mathrm{~mm}]}\end{array}$ & $\begin{array}{c}V_{z} \\
{[\mathrm{~mm} / \mathrm{y}]}\end{array}$ & $\begin{array}{c}m_{z} \\
{[\mathrm{~mm}]}\end{array}$ & $\begin{array}{c}V_{n} \\
{[\mathrm{~mm} / \mathrm{y}]}\end{array}$ & $\begin{array}{c}m_{n} \\
{[\mathrm{~mm}]}\end{array}$ & $\begin{array}{c}V_{e} \\
{[\mathrm{~mm} / \mathrm{y}]}\end{array}$ & $\begin{array}{c}m_{e} \\
{[\mathrm{~mm}]}\end{array}$ \\
\hline 81 & 0.6 & 0.4 & 1.3 & 0.5 & -2.5 & 0.4 & -2.6 & 0.5 & 0.9 & 0.5 \\
82 & 0.6 & 0.4 & 1.4 & 0.5 & -2.7 & 0.4 & -2.7 & 0.5 & 1.0 & 0.5 \\
83 & 0.5 & 0.4 & 1.8 & 0.6 & -2.9 & 0.4 & -2.9 & 0.6 & 1.4 & 0.6 \\
17 & 0.6 & 0.5 & 2.3 & 0.7 & -3.2 & 0.5 & -3.3 & 0.6 & 1.9 & 0.7 \\
12 & 0.7 & 0.4 & -0.3 & 0.4 & -1.6 & 0.4 & -1.6 & 0.5 & -0.7 & 0.5 \\
11 & 0.4 & 0.5 & 1.5 & 0.6 & -2.5 & 0.5 & -2.5 & 0.6 & 1.1 & 0.7 \\
26 & 1.4 & 0.6 & -1.3 & 0.4 & -1.5 & 0.6 & -1.6 & 0.2 & -1.8 & 0.3 \\
16 & 0.8 & 0.3 & 0.5 & 0.4 & -2.2 & 0.3 & -2.3 & 0.4 & 0.1 & 0.4 \\
VERI & 1.2 & 0.1 & 0.0 & 0.1 & -2.2 & 0.1 & -2.3 & 0.4 & -0.5 & 0.3 \\
PLA1 & 1.0 & 0.1 & 0.1 & 0.1 & -2.1 & 0.1 & -2.2 & 0.3 & -0.4 & 0.2 \\
BUHO & 0.8 & 0.2 & 1.4 & 0.1 & -2.8 & 0.2 & -2.9 & 0.5 & 0.9 & 0.4 \\
LOZE & 0.9 & 0.3 & 0.6 & 0.1 & -2.4 & 0.3 & -2.5 & 0.5 & 0.2 & 0.4 \\
VLAD & 0.6 & 0.2 & 1.8 & 0.1 & -2.9 & 0.1 & -2.9 & 0.4 & 1.3 & 0.3 \\
BREZ & 0.4 & 0.2 & 1.3 & 0.1 & -2.4 & 0.2 & -2.4 & 0.5 & 1.1 & 0.4 \\
SLIV & 0.4 & 0.2 & 1.8 & 0.1 & -2.7 & 0.2 & -2.8 & 0.5 & 1.5 & 0.4 \\
\hline
\end{tabular}

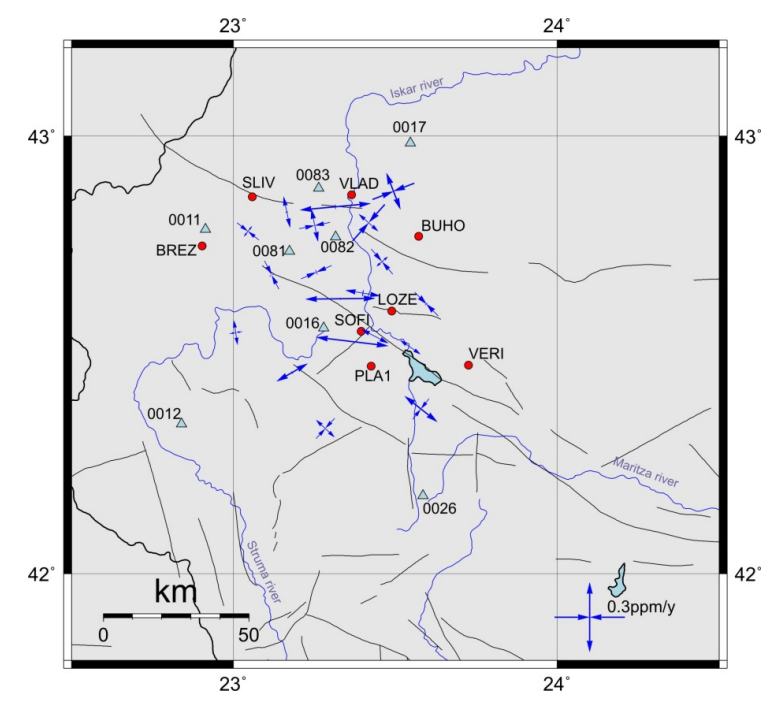

Figure 3. Principal axes of the horizontal strain rate tensors in the central west Bulgaria results from combined GPS and triangulation data solution. The slim lines show the active faults.

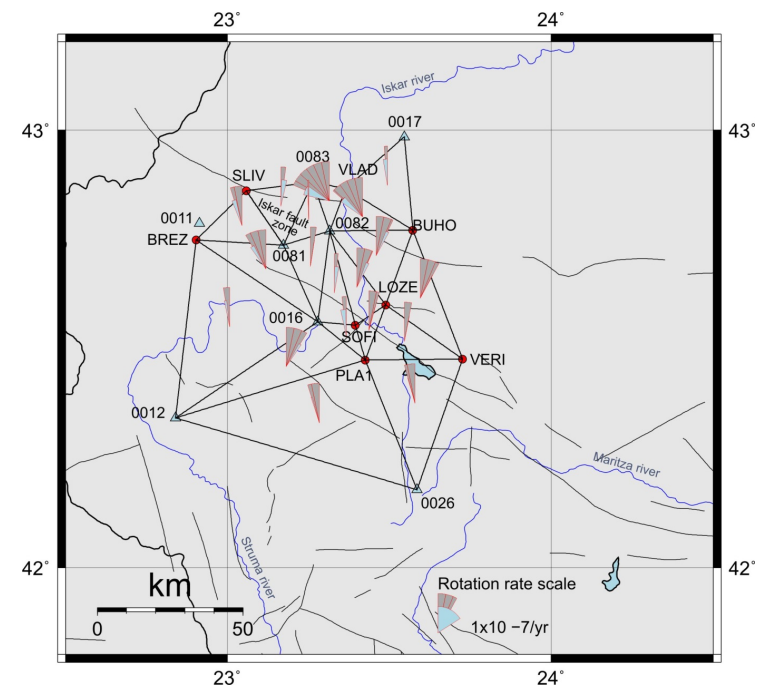

Figure 4. Rotation rates in Delaunay triangles.
Georgiev (2011). The important result obtained in this study is that the rotations in the triangles to the north of Iskar fault zone (northwest to southeast) have counter-clockwise directions and those in the triangles located to the south of the fault zone have clockwise directions (Fig. 4).

\section{Conclusions}

The results show that the general tendency of movement of the points in the region of Central West Bulgaria is in the south direction with respect to the stable Eurasia, which is in line with the extensive movement of southern Bulgaria and northern Greece. The stations with combined GPS-triangulation velocities show similar behaviour as the stations with only GPS measurements. The accuracy of the estimated station velocities strongly depends on their observation history. From the analysis of the results, it is clear that rotations in the triangles located to the north of the Iskar fault zone (northwest to southeast) have counter-clockwise directions and those in the triangles located to the south of the fault zone have clockwise directions. The difference in these directions shows the existence of the recent activity in the area. The results of this study can be used to clarify the geological and tectonic environment. However, longer periods of observation are necessary to acquire more accurate results.

\section{References}

Barrier, E., Chamot-Rooke, N., and Giordano, G. (2004). Geodynamic maps of the Mediterranean - sheet 1: Tectonics and kinematics. Commission for the Geological Map of the World (CGMW) \& Unesco, France.

Burchfiel, C. B., Nakov, R., Tzankov, T., and Royden, L. H. (2000). Cenozoic extension in Bulgaria and northern Greece: the northern part of the Aegean extensional regime. $\mathrm{Ge}$ ological Society, London, Special Publications, 173(1):325-352, doi:10.1144/GSL.SP.2000.173.01.16.

Dimitrov, N. and Georgiev, I. (2011). Crustal strain from GPS and triangulation data in Central Western Bulgaria. Review of the Bulgarian Geological Society, 72(1-3):27-32.

Dong, D. (1993). The horizontal velocity field in southern California from a combination of terrestrial and space-geodetic data. $\mathrm{PhD}$ thesis, Massachusetts Institute of Technology.

Dong, D., Herring, T., and King, R. W. (1998). Estimating regional deformation from a combination of space and terrestrial geodetic data. Journal of Geodesy, 72(4):200-214, doi:10.1007/s001900050. 
Kotzev, V., Nakov, R., Burchfiel, B., and Dimirov, N. (2005). Crustal motion in Central West Bulgaria from triangulation and GPS data. Comptes rendus de l'Academie Blugare des Sciences, 58(6):699-704.

Kotzev, V., Nakov, R., Georgiev, T., Burchfiel, B., and King, R. (2006). Crustal motion and strain accumulation in western Bulgaria. Tectonophysics, 413(3-4):127-145, doi:10.1016/j.tecto.2005.10.040.

Romero, M. and Berber, M. M. (2018). Subsidence determination in the Central Valley, California. Reports on Geodesy and
Geoinformatics, 106:35-42, doi:10.2478/rgg-2018-0012.

Yearbook of the State Geographic Institute (1927). Yearbook of the State Geographic Institute for 1923, 1924, 1925, and 1926 (in Bulgarian). Sofia, Ministry of War.

Yearbook of the State Geographic Institute (1929). Yearbook of the State Geographic Institute for 1927 and 1928 (in Bulgarian). Sofia, Ministry of War.

Yearbook of the State Geographic Institute (1932). Yearbook of the State Geographic Institute for 1931 (in Bulgarian). Sofia, Ministry of War. 